\title{
Ventilatory function in workers exposed to low levels of toluene diisocyanate: a six-month follow-up
}

\author{
JOHN M. PETERS, RAYMOND L. H. MURPHY, AND \\ BENJAMIN G. FERRIS, Jr. \\ Kresge Center for Environmental Health, Harvard School of Public Health, Boston, \\ Massachusetts
}

\begin{abstract}
Peters, John M., Murphy, Raymond L. H., and Ferris, Benjamin, G., Jr. (1969). Brit. J. industr. Med., 26, 115-120. Ventilatory function in workers exposed to low levels of toluene diisocyanate: a six-month follow-up. Thirty-four workers exposed to toluene diisocyanate during production of polyurethane foam were examined with a respiratory questionnaire and tests of ventilatory capacity. The tests of pulmonary function were conducted on Monday morning and afternoon and on Tuesday morning and afternoon. Twenty-eight of these 34 workers had been examined with the same tests six months earlier. On Monday a mean change in the one-second forced expiratory volume (F.E.V.1.0 $)$ of -0.161 . occurred that did not return to the baseline value (Monday a.m.) on Tuesday morning. A statistically significant decrease in all the measurements of ventilatory capacity except the forced vital capacity occurred over the six months in the 28 workers. The F.E.V. .1 .0 fell an average of 0.141 . and flow rates at $75 \%$, $50 \%, 25 \%$, and $10 \%$ of vital capacity also decreased significantly. There was a highly significant correlation coefficient $(r=0.72)$ between one-day changes in F.E.V.1.0 (measured six months earlier) and six-month changes in F.E.V. .1.0. . Workers with respiratory symptoms (cough and/or phlegm) demonstrated greater falls in F.E.V.1.0 than did asymptomatic workers.
\end{abstract}

All air concentrations of toluene diisocyanate measured during this study were below the threshold limit value (0.02 p.p.m.).

The production and use of polyurethane foam have been increasing over the past several years. Toluene diisocyanate (TDI) is the most frequently used polymerizing agent in this process.

TDI is well known for its toxicity in low concentrations. The threshold limit value (T.L.V.) for workers exposed to this material, set by the American Conference of Governmental Industrial Hygienists (A.C.G.I.H.), is 0.02 p.p.m., a ceiling limit not to be exceeded. A review of the clinical features in workers affected by exposure to TDI was published by Brugsch and Elkins (1963). Manifestations ranged from upper respiratory irritation to 'status asthmaticus'. They stated that workers removed from exposure rapidly recovered but that some workers when re-exposed to even minimal concentrations developed characteristic chest tightness and bronchospasm.

Gandevia (1963) and Williamson (1965) have observed acute changes in pulmonary function (timed vital capacity) in workers exposed to concentrations of TDI probably much greater than the current T.L.V. However, air concentrations of TDI were not determined during the time of exposure.

Peters, Murphy, Pagnotto, and VanGanse (1968) studied workers exposed to TDI at concentrations less than T.L.V. Measurements of pulmonary func- 
tion were made during the work week on Monday morning, Monday afternoon, and Friday afternoon on 34 workers. Significant decreases in the forced expiratory volume in one second (F.E.V.1.0) from the morning value were noted on Monday afternoon and Friday afternoon. There was also an association between the size of this decrease and respiratory symptoms; that is, symptomatic workers showed greater declines in F.E.V.1.0 than asymptomatic workers. The possibility that these acute changes in ventilatory capacity are associated with or lead to chronic or cumulative pulmonary changes must be considered. This possibility has been suggested by Munn (1965) although there is little or no evidence to support it.

This study was conducted primarily to answer two questions: Does exposure to TDI cause any cumulative or chronic effect on ventilatory capacity? Are there ways to predict which workers will be sensitive to this material?

To try to answer these questions we repeated our measurements of ventilatory capacity in the same factory and on the same workers six months after our initial observations noted above.

\section{Methods}

Of the 34 workers seen six months previously, 28 were still employed in this factory. Measurements of pulmonary function were conducted on Monday morning and afternoon and on Tuesday morning and afternoon. The studies included forced vital capacity (F.V.C.), F.E.V.1.0, the ratio of F.E.V.1.0/F.V.C. and flow rates at $75 \%, 50 \%$, $25 \%$ and $10 \%$ of vital capacity. The flow rates were determined by methods described previously (Peters and Ferris, 1967). Analysis of the tracings and the determination of flow rates were made by a single observer without knowledge of when the data were collected. All flows and volumes were corrected to B.T.P.S. (for differences in ambient and body temperature and water saturation). The spirometer was calibrated by positive volume displacement and the accuracy of its dynamic characteristics was verified. The value used for analysis was the mean obtained from three satisfactory forced vital capacities.

To determine the possible cumulative effect of six months' exposure, we compared the Monday morning values of December 1966 with those of May 1967. To assess the completeness of overnight recovery, Tuesday morning values were compared with Monday morning and afternoon values.

We had complete smoking histories, occupational histories, and respiratory symptoms from questionnaires of six months earlier. From this information symptomatic workers could be compared with asymptomatic workers and smokers with non-smokers with regard to changes in ventilatory capacity.

In addition to the 28 workers seen six months previously, six new employees were studied. Therefore, acute changes were measured in 34 workers, while the changes after six months were measured in 28 workers.

An assessment of cough and sputum (independent of the questionnaire) was made by instructing each worker to cough up as much sputum as possible on Monday morning and afternoon. One observer noted whether the subject had a 'dry' cough or a 'loose' cough or produced sputum. Judgements about 'dry' or 'loose' were made by ear. Sputum samples were transferred to glass slides, stained with Wright's stain, and examined microscopically for eosinophils.

Aerometric determinations for the concentration of TDI were made at all locations within the plant where workers were principally concentrated. These measurements were made on the first working day (Monday) by the Marcali (1957) method, allowing detection of 0.0005 p.p.m. with long sampling times.

A detailed description of this factory appears elsewhere (Peters et al., 1968).

Statistical tests will be termed significant when the probability of receiving the result by chance alone is less than 0.05 .

\section{Results}

The concentrations of TDI on Monday ranged from 0.0000 to 0.0120 p.p.m. (see Table 1). Air sampling

TABLE 1

AEROMETRIC DATA ON TDI (P.P.M.)

\begin{tabular}{|c|c|c|c|}
\hline & Location & Range & $\begin{array}{l}\text { No. of } \\
\text { samples } \\
\text { taken }\end{array}$ \\
\hline May 1966 & $\begin{array}{l}\text { Pouring area } \\
\text { Unloading area }\end{array}$ & $\begin{array}{l}0.003-0.008 \\
0.000-0.003\end{array}$ & $\begin{array}{l}2 \\
2\end{array}$ \\
\hline $\begin{array}{c}\text { December } \\
1966\end{array}$ & $\begin{array}{l}\text { Pouring area } \\
\text { Unloading area } \\
\text { Packing and } \\
\text { shipping } \\
\text { Machine shop } \\
\text { Rotational casting }\end{array}$ & $\begin{array}{c}0.0010-0.0030 \\
0.0000-0.0005 \\
0.0005 \\
0.0000 \\
0.0000\end{array}$ & $\begin{array}{l}8 \\
6 \\
2 \\
2 \\
2\end{array}$ \\
\hline May 1967 & $\begin{array}{l}\text { Pouring area } \\
5 \text { to } 10 \mathrm{ft} \text {. from } \\
\text { pouring } \\
\text { Unloading } \\
\text { Stripping moulds }\end{array}$ & $\begin{array}{l}0.0090-0.0120 \\
0.0045-0.0050 \\
0.0000-0.0010 \\
0.0040-0.0050\end{array}$ & $\begin{array}{l}2 \\
2 \\
2 \\
2\end{array}$ \\
\hline
\end{tabular}

data are summarized in this table for the previous year. Concentrations were always highest near the pouring area and very low in other areas (0.0050 p.p.m. or below). Multiple samples taken during two days six months apart for this study were all considerably below 0.02 p.p.m. These samples were taken during ordinary, full-production pouring.

\section{Changes over two days}

The mean values for F.V.C. are listed in Table 2. On both Monday and Tuesday statistically significant decreases in F.V.C. occurred. There was essentially complete recovery overnight of this parameter. 
TABLE 2

MEANS OF F.V.C. (LITRES) IN 34 WORKERS Exposed to TDI to show ACute Changes

\begin{tabular}{|c|c|c|c|}
\hline & Morning & $P^{1}$ & Afternoon \\
\hline Monday & $4.801 .--$ & $<0.02--$ & $4 \cdot 721$. \\
\hline .. & n.s. & & n.s. \\
\hline Tuesday & $4.791 . .-$ & $<0.05--$ & 4.721. \\
\hline
\end{tabular}

${ }^{1}$ Paired $t$ test comparing the difference of means.

\section{TABLE 3}

MEANS OF F.E.V.1.0 (LITRES) IN 34 WORKERS EXPOSED to TDI to SHOW ACUTE Changes

\begin{tabular}{|c|c|c|c|c|}
\hline & & Morning & $P^{1}$ & Afternoon \\
\hline Monday & . & $3.921 .--$ & $<0.01--$ & 3.761. \\
\hline $\mathbf{P}^{\mathbf{l}} \quad \ldots$ & . & $<0.01$ & $<0.01->$ & n.s. \\
\hline Tuesday & . & $3.821 .--$ & n.s. & -3.791 \\
\hline
\end{tabular}

${ }^{1}$ Paired $t$ test comparing difference of means.

There was a greater decrease in the F.E.V..$_{\cdot 1 \cdot 0}$ on Monday than in the F.V.C. (see Table 3). This change of $0.16 \mathrm{l}$. was statistically significant. The Tuesday morning mean was still significantly depressed below the Monday morning baseline, although a very slight recovery occurred. On Monday, individual changes in F.E.V. .1.0 ranged from -1.81 l. to +0.131 . Decreases exceeding 0.20 1 . were observed in 10 of the 34 workers.

\section{Changes over six months}

In the interval between December 1966 and May 1967 , the group of 28 workers showed a statistically

TABLE 4

Mean Values from the Measurements of VeNTILATORY CAPACITY OF 28 WORKERS

EXPOSED TO TDI BETWEen DeCEMBER AND MAY

\begin{tabular}{|c|c|c|c|c|}
\hline Measurement & $\begin{array}{c}\text { December } \\
1966\end{array}$ & $\begin{array}{l}\text { May } \\
1967\end{array}$ & Difference & $P^{1}$ \\
\hline 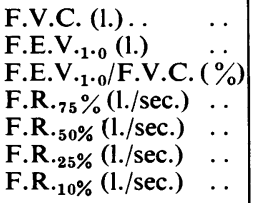 & $\begin{array}{r}4.75 \\
4.07 \\
85.70 \\
8.41 \\
5.48 \\
2.40 \\
0.78\end{array}$ & $\begin{array}{r}4.84 \\
3.93 \\
81 \cdot 20 \\
7.64 \\
4.55 \\
1.83 \\
0.57\end{array}$ & $\begin{array}{r}0.09 \\
-0.14 \\
-4.50 \\
-0.77 \\
-0.93 \\
-0.57 \\
-0.21\end{array}$ & $\begin{aligned} & \text { n.s. } \\
< & 0.02 \\
< & 0.01 \\
< & 0.05 \\
< & 0.01 \\
< & 0.01 \\
< & 0.01\end{aligned}$ \\
\hline
\end{tabular}

${ }^{1}$ From paired $t$ tests. significant decrease in F.E.V.$_{1 \cdot 0}$ (Table 4). The ratio of F.E.V.1.0 $/ F . V . C$. fell $4.5 \%$ and the decline in flow rates was also significant and ranged from 0.21 to $0.93 \mathrm{l} . / \mathrm{sec}$. Twenty of the 28 workers showed reductions in F.E.V $\cdot_{\cdot 1 \cdot 0}$ over the six months, ranging from -0.011 . to -1.041 . There was an insignificant change in the mean value for F.V.C. during this interval.

To determine the effect of smoking on the response to TDI, the 28 workers were divided into two groups -12 current smokers and 16 current non-smokers. The means of the six-month differences are compared in Table 5. In both groups, the mean values for all measurements except F.V.C. tended to decline over the six-month period. The expiratory flow rates (F.R.) at high lung volume (F.R. ${ }_{75} \%$ ) in the smokers and low lung volume (F.R. ${ }_{25} \%$ and F.R. ${ }_{10} \%$ ) in the non-smokers were the most affected over this period of observation and differed significantly between smoking groups. Although these differences between the flow rates of smokers and non-smokers are statistically significant, the exact meaning of these differences is not clear.

Dividing the 28 workers by lifetime smoking habits (ever smoked $v$. never smoked) does not alter the relationship noted above (see Table 6).

Table 7 relates the six-month changes in F.E.V.V.1.0 to respiratory symptoms. Although few workers had symptoms, it was common for those who did to have greater declines in their F.E.V.1.0. For example, the workers who had cough and phlegm (the first 11 questions) had significantly greater changes than did the asymptomatic workers.

The average decrease in F.E.V. $\cdot_{1 \cdot 0}$ for those eight workers with sputum in the morning and afternoon was $0.38 \mathrm{l}$. (see Table 8). The mean decline in F.E.V.1.0 for the other 17 workers was 0.051 . The status of the cough in the morning ('dry', 'loose' or sputum) bore a strong relationship to the changes in F.E.V.1.0 over the previous six months: a 'dry' cough was associated with no change, a 'loose' cough with slight changes, and a productive cough with sizable changes. Only one worker had eosinophils in his sputum; his F.E.V.1.0 $-0.93 \mathrm{l}$. and a one-day change of $-0.42 \mathrm{l}$. No worker had a past history of asthma.

A high degree of correlation existed between the one-day change in F.E.V.1.0 and the six-month change in F.E.V.$_{1 \cdot 0}(r=0.72)$. There was no significant correlation between age, length of exposure, current smoking habits (amount per day), and any of the changes in ventilatory function. Many of the changes in ventilatory function were significantly correlated with lifetime packs smoked and duration of smoking (in years). For simplicity, only the statistically significant correlations between F.E.V.1.0 and other variables are presented in Table 9. Both lifetime packs and duration of smoking correlated 
TABLE 5

Mean SiX-month Differences in Ventilatory Capacity of 28 Workers Exposed to TDI by Current SMoking Category

\begin{tabular}{|c|c|c|c|c|c|c|c|c|}
\hline \multicolumn{4}{|c|}{ Measurement } & \multicolumn{2}{|c|}{$n=16 \stackrel{\text { Non-smoker }}{P^{1}}$} & \multicolumn{2}{|c|}{${ }_{2}^{\text {Smoker }}$} & $\begin{array}{c}\begin{array}{c}\text { Differences } \\
\text { between smokers } \\
\text { and non-smokers } P^{2}\end{array} \\
\text { n.s. }\end{array}$ \\
\hline $\begin{array}{ll}\text { F.V.C. (1.) } \ldots & \ldots \\
\text { F.E.V. } 1.0(1 .) & \ldots \\
\text { F.R. } 75 \%(1 . / \mathrm{sec} .) & \ldots \\
\text { F.R. } 50 \%(1 . / \mathrm{sec} .) & \ldots \\
\text { F.R. } 25 \%(1 . / \mathrm{sec} .) & \ldots \\
\text { F.R. } 10 \%(1 . / \mathrm{sec} .) & \ldots\end{array}$ & $\begin{array}{l}\ldots \\
\cdots \\
\cdots \\
\cdots \\
\cdots \\
\cdots\end{array}$ & $\begin{array}{l}\cdots \\
\cdots \\
\cdots \\
\cdots \\
\cdots\end{array}$ & $\begin{array}{l}\ldots \\
\ldots \\
\cdots \\
\cdots \\
\cdots\end{array}$ & $\begin{array}{l}+0.16 \\
-0.11 \\
-0.19 \\
-0.99 \\
-0.75 \\
-0.29\end{array}$ & $\begin{array}{l}<0.02 \\
\text { n.s. } \\
\text { n.s. } \\
<0.01 \\
<0.01 \\
<0.01\end{array}$ & $\begin{array}{r}0.00 \\
-0.18 \\
-1.53 \\
-0.83 \\
-0.34 \\
-0.11\end{array}$ & $\begin{array}{l}\text { n.s. } \\
\text { n.s. } \\
<0.01 \\
<0.02 \\
<0.05 \\
\text { n.s. }\end{array}$ & $\begin{array}{c}\text { n.s. } \\
\text { n.s. } \\
<0.02 \\
\text { n.s. } \\
<0.05 \\
<0.05\end{array}$ \\
\hline
\end{tabular}

${ }^{1}$ Significance of within group differences by paired $t$ test.

${ }^{2}$ Significance of between smoking group differences by $t$ test.

TABLE 6

Mean Six-month Differences in Pulmonary Function of 28 Workers Exposed to TDI BY LifETIME SMOKING CATEGORY

\begin{tabular}{|c|c|c|c|c|c|c|c|c|}
\hline \multicolumn{4}{|c|}{ Measurement } & \multicolumn{2}{|c|}{$\begin{array}{l}\text { Never smoked } \\
n=11 \quad P^{1}\end{array}$} & \multicolumn{2}{|c|}{$n=17 \quad$ Ever smoked } & $\begin{array}{c}\text { Differences between } \\
\text { never smoked and } \\
\text { ever smoked } P^{2}\end{array}$ \\
\hline $\begin{array}{ll}\text { F.V.C. (1.) } & \ldots \\
\text { F.E.V.1.0 (1.) } & \ldots \\
\text { F.R. } 75 \%(1 . / \mathrm{sec} .) & \ldots \\
\text { F.R. } 50 \%(1 . / \mathrm{sec} .) & \ldots \\
\text { F.R. } 25 \%(1 . / \mathrm{sec} .) & \ldots \\
\text { F.R. } 10 \%(1 . / \mathrm{sec} .) & \ldots\end{array}$ & $\begin{array}{l}\cdots \\
\cdots \\
\cdots \\
\cdots \\
\cdots \\
\cdots\end{array}$ & $\begin{array}{l}\cdots \\
\cdots \\
\cdots \\
\cdots \\
\cdots \\
\cdots\end{array}$ & $\begin{array}{l}\cdots \\
\cdots \\
\cdots \\
\cdots \\
\cdots\end{array}$ & $\begin{array}{l}+0.14 \\
-0.08 \\
-0.23 \\
-1.03 \\
-0.71 \\
-0.31\end{array}$ & $\begin{array}{l}\text { n.s. } \\
\text { n.s. } \\
\text { n.s. } \\
<0.01 \\
<0.01 \\
<0.01\end{array}$ & $\begin{array}{r}0.06 \\
-0.18 \\
-1 \cdot 11 \\
-0.86 \\
-0.49 \\
-0.15\end{array}$ & $\begin{aligned} & \text { n.s. } \\
&<0.02 \\
&<0.02 \\
&<0.01 \\
&<0.01 \\
&<0.05\end{aligned}$ & $\begin{array}{l}\text { n.s. } \\
\text { n.s. } \\
\text { n.s. } \\
\text { n.s. } \\
\text { n.s. } \\
\text { n.s. }\end{array}$ \\
\hline
\end{tabular}

${ }^{1}$ Significance of within group differences by paired $t$ test.

${ }^{2}$ Significance of between smoking group differences by $t$ test.

significantly with one-day and six-month changes in F.E.V.1.0. Could either of these variables account for the correlation between one-day and six-month changes? When the smoking variables were held constant, the strong correlation still remained $\left(r_{12 \cdot 34}=0 \cdot 60\right)$.

\section{Discussion}

Changes in ventilatory function during the working day in workers exposed to TDI have been demonstrated. These changes occur at air concentrations of TDI below the current T.L.V. We have made morning and afternoon measurements on ourselves (the five persons involved in this study) in our own laboratory on many occasions with no changes in F.E.V.1.0 occurring. However, in the factory, when exposed to TDI the mean drop in our F.E.V.1.0 values was 0.131 ., a change similar to that of the workers. In addition, we have studied a group of 18 welders with the same methods, and no statistically significant changes occurred during the day.
The demonstration of statistically significant changes in ventilatory function over the six months of observation suggests a cumulative effect of exposure to TDI. While the mean change in F.E.V.1.0 was small $(-0 \cdot 141$.$) , other evidence suggests that it$ was much greater than expected from ageing. By the prediction formulae of Ferris, Anderson, and Zickmantel (1965), the change in F.E.V.1.0 months in these workers (based on smoking habits, height, sex, and age) would be -0.021 . Higgins, Gilson, Ferris, Waters, Campbell, and Higgins (1968) measured the F.E.V.1.0 in the same individuals nine years apart. They noted a rate of change over this period that was smaller than the rate of change we noted.

Seasonal variation in pulmonary function has been suggested as a possibility by McKerrow (1964). He noted that his measurements were highest in the summer and lowest in the winter and that there was an association between temperature and performance. If this seasonal factor operated in our study, it would tend to reduce the differences that we noted 
TABLE 7

Positive Responses to QuestionNaIRe OF Respiratory Symptoms COMPARed With Drop IN F.E.V.1·0 DURING 6 MONTHS IN 28 TDI WORKERS

\begin{tabular}{|c|c|c|c|c|c|c|c|c|c|c|}
\hline \multicolumn{7}{|c|}{ Respiratory symptom } & $\begin{array}{l}\text { Yes } \\
\text { responses }\end{array}$ & $\%$ & $\begin{array}{l}\text { Drop in F.E. } V_{\cdot 1 \cdot 0}{ }^{1} \\
\quad \text { (litres) }\end{array}$ & $P^{2}$ \\
\hline \multicolumn{3}{|c|}{$\begin{array}{l}\text { Cough in morning in winter ... } \\
\text { Cough in morning in summer } \\
\text { Cough during day or night in winter } \\
\text { Cough during day or night in summer }\end{array}$} & $\begin{array}{l}\cdots \\
\cdots \\
\cdots \\
\cdots\end{array}$ & $\begin{array}{l}\cdots \\
\cdots \\
\cdots \\
\cdots\end{array}$ & $\begin{array}{l}\cdots \\
\cdots \\
\cdots \\
\cdots \\
\cdots\end{array}$ & $\begin{array}{l}\cdots \\
\cdots \\
\cdots \\
\cdots \\
\cdots\end{array}$ & $\begin{array}{l}3 \\
3 \\
4 \\
4 \\
5\end{array}$ & $\begin{array}{l}11 \\
11 \\
14 \\
14 \\
18\end{array}$ & $\begin{array}{l}-0.70 \\
-0.70 \\
-0.66 \\
-0.64 \\
-0.55\end{array}$ & $\begin{array}{l}<0.01 \\
<0.01 \\
<0.01 \\
<0.01 \\
<0.01\end{array}$ \\
\hline \multicolumn{3}{|c|}{$\begin{array}{l}\text { Phlegm in morning in winter } \\
\text { Phlegm in morning in summer } \\
\text { Phlegm during day or night in winter } \\
\text { Phlegm during day or night in summer } \\
\text { Phlegm 3+ months per year }\end{array}$} & $\begin{array}{l}\cdots \\
\cdots \\
\cdots \\
\cdots\end{array}$ & $\begin{array}{l}\cdots \\
\cdots \\
\cdots \\
\cdots \\
\cdots\end{array}$ & $\begin{array}{l}\cdots \\
\cdots \\
\cdots \\
\cdots\end{array}$ & $\begin{array}{l}\cdots \\
\cdots \\
\cdots \\
\cdots \\
\cdots\end{array}$ & $\begin{array}{l}8 \\
7 \\
5 \\
5 \\
8\end{array}$ & $\begin{array}{l}29 \\
25 \\
18 \\
18 \\
29\end{array}$ & $\begin{array}{l}-0.40 \\
-0.45 \\
-0.57 \\
-0.57 \\
-0.40\end{array}$ & $\begin{array}{l}<0.05 \\
<0.01 \\
<0.01 \\
<0.01 \\
<0.05\end{array}$ \\
\hline \multicolumn{4}{|c|}{ Increase in cough and phlegm lasting $3+$ weeks } & . & . & . & 9 & 32 & $-0 \cdot 28$ & $<0.05$ \\
\hline Haemoptysis .. & . & . & . & . & . & . & 1 & 4 & -0.01 & n.s. \\
\hline \multicolumn{4}{|c|}{$\begin{array}{l}\text { Breathlessness on slight hill or hurrying on level } \\
\text { Breathlessness for } 2 \text { or more winters }\end{array}$} & $\begin{array}{l}\cdots \\
\cdots\end{array}$ & $\begin{array}{l}\cdots \\
\cdots\end{array}$ & $\begin{array}{l}\cdots \\
\cdots\end{array}$ & $\begin{array}{l}4 \\
2\end{array}$ & $\begin{array}{l}7 \\
7\end{array}$ & $\begin{array}{l}-0.08 \\
-0.08\end{array}$ & $\begin{array}{l}\text { n.s. } \\
\text { n.s. }\end{array}$ \\
\hline \multicolumn{2}{|c|}{$\begin{array}{l}\text { Wheezing in chest with colds } \\
\text { Wheezing in chest apart from colds } \\
\text { Wheezing most days or nights }\end{array}$} & $\begin{array}{l}\cdots \\
\cdots \\
\cdots\end{array}$ & $\begin{array}{l}\cdots \\
\cdots \\
.\end{array}$ & $\begin{array}{l}\cdots \\
\cdots \\
\cdots\end{array}$ & $\begin{array}{l}\cdots \\
\cdots \\
\cdots\end{array}$ & $\begin{array}{l}. \\
\cdots \\
.\end{array}$ & $\begin{array}{r}12 \\
3 \\
1\end{array}$ & $\begin{array}{r}43 \\
11 \\
4\end{array}$ & $\begin{array}{l}-0.29 \\
-0.38 \\
-0.93\end{array}$ & $\begin{array}{l}\text { n.s. } \\
\text { n.s. } \\
-\end{array}$ \\
\hline $\begin{array}{l}\text { Nasal catarrh in winter } \\
\text { Nasal catarrh in summer }\end{array}$ & $\begin{array}{l}\cdots \\
\cdots\end{array}$ & $\begin{array}{l}\cdots \\
\cdots\end{array}$ & $\begin{array}{l}\cdots \\
\cdots\end{array}$ & $\begin{array}{l}\cdots \\
\cdots\end{array}$ & $\begin{array}{l}\cdots \\
\cdots\end{array}$ & $\begin{array}{l}\cdots \\
\cdots\end{array}$ & $\begin{array}{l}9 \\
4\end{array}$ & $\begin{array}{l}32 \\
14\end{array}$ & $\begin{array}{l}-0 \cdot 18 \\
-0.05\end{array}$ & $\begin{array}{l}\text { n.s. } \\
\text { n.s. }\end{array}$ \\
\hline Colds go to chest & $\ldots$ & $\ldots$ & .. & $\ldots$ & $\ldots$ & $\ldots$ & 10 & 36 & -0.37 & $<0.05$ \\
\hline
\end{tabular}

${ }^{1}$ Mean drop for entire group $=0.14 \mathrm{l}$.

${ }^{2}$ From $t$ tests, comparing yes and no responses for each symptom.

TABLE 9

TABLE 8

Relationship OF COUgh and SpUtum (MONDAY A.M. TO MONDAY P.M.) TO MeaN

ChANGE IN F.E.V.1.0 OVER 6 MONTHS (25 WORKERS)

\begin{tabular}{l|c|c|c|c}
\hline \multirow{2}{*}{\begin{tabular}{l|l|} 
Monday \\
p.m.
\end{tabular}} & \multicolumn{3}{|c}{ Monday a.m. } \\
\cline { 2 - 5 } & $\begin{array}{c}\text { 'Dry' } \\
\text { cough }\end{array}$ & $\begin{array}{c}\text { 'Loose' } \\
\text { cough }\end{array}$ & $\begin{array}{c}\text { Produced } \\
\text { sputum }\end{array}$ \\
\hline & $\begin{array}{c}\text { cough } \\
\text { 'Loose' } \\
\text { cough }\end{array}$ & $\begin{array}{c}-0.021 . \\
(\mathrm{n}=7)\end{array}$ & & \\
\cline { 2 - 5 } & $\begin{array}{c}\text { Produced } \\
\text { sputum }\end{array}$ & $\begin{array}{l}0.001 . \\
(\mathrm{n}=5)\end{array}$ & $\begin{array}{c}-0.121 . \\
(\mathrm{n}=2)\end{array}$ & $\begin{array}{c}-0.381 . \\
(\mathrm{n}=8)\end{array}$ \\
\hline
\end{tabular}


rather than account for them. Any effect of training on the forced vital capacity would likewise tend to reduce the differences we noted.

The ability of the one-day change in F.E.V.1.0 to predict the six-month change $(r=0.72)$ offers promise as a screening tool for the selection of workers for this industry. Likewise, the simple assessment of respiratory symptoms by either of the ways described in this study appears to be useful in detecting workers likely to be affected by exposure to TDI.

The relationship of smoking to the changes in ventilatory capacity was not entirely clear. There was a greater change in F.E.V. $\cdot_{\cdot 1 \cdot 0}$ over six months among current smokers than among non-smokers; however, the difference was not statistically significant. Larger sample sizes would be necessary to clarify this. While smoking (lifetime packs and duration) correlated with one-day and six-month changes in F.E.V.1.0, the correlation between one-day and sixmonth changes in F.E.V.1.0 was not appreciably altered by holding smoking constant.

It appears that TDI in concentrations below T.L.V. can exert a two-fold effect. The first is the acute effect noted in most of these workers in a matter of hours from which overnight recovery is incomplete. The second is the cumulative effect, occurring in this study over a period of six months. How reversible this latter reaction is with cessation of exposure is unknown. Additional studies are planned to answer this question.

This work was supported by U.S. Public Health Service Grants UI 00505 and ES 00002.

\section{References}

Brugsch, H. G., and Elkins, H. B. (1963). Toluene di-isocyanate (TDI) toxicity. New Engl. J. Med., 268, 353-357.

Ferris, B. G., Anderson, D. O., and Zickmantel, R. (1965). Prediction values for screening tests of pulmonary function. Amer. Rev. resp. Dis., 91, 252-261.

Gandevia, B. (1963). Studies of ventilatory capacity and histamine response during exposure to isocyanate vapour in polyurethane foam manufacture. Brit. J. industr. Med., 20, 204-209.

Higgins, I. T. T., Gilson, J. C., Ferris, B. G., Waters, E., Campbell, H. M., and Higgins, M. W. (1968). Chronic respiratory disease in an industrial town. Amer. J. publ. Hlth, 58, 1667-1676.

Marcali, K. (1957). Microdetermination of toluene diisocyanates in atmosphere. Analyt. Chem., 29, 552-558.

McKerrow, C. B. (1964). Chronic respiratory disease in Great Britain. Arch. environm. Hlth, 8, 174-179.

Munn, A. (1965). Hazards of isocyanates. Ann. occup. Hyg., 8, 163-169.

Peters, J. M., and Ferris, B. G. (1967). Smoking, pulmonary function, and respiratory symptoms in a college-age group. Amer. Rev. resp. Dis., 95, 774-782.

, Murphy, R. L. H., Pagnotto, L. D., and Van Gane, W. F. (1968). Acute respiratory effects in workers exposed to low levels of toluene diisocyanate. Arch. environm. Hlth, 16, 642-647.

Williamson, K. S. (1965). Studies of diisocyanate workers. Trans. Ass. industr. med. Offrs, 15, 29-35.

Received for publication September 4, 1968. 